\title{
Distribution of Risk Factors in Patients with Premature Coronary, Supra-Aortic Branches and Peripheral Atherosclerotic Disease
}

\author{
Djordje Radak ${ }^{\mathrm{a}}$ Srdjan Babic ${ }^{\mathrm{a}}$ Miodrag Peric ${ }^{\mathrm{b}}$ Petar Popov \\ Slobodan Tanaskovic ${ }^{a}$ Dusan Babic ${ }^{a}$ Dario Jocic ${ }^{a}$ Petar Otasevic ${ }^{c}$

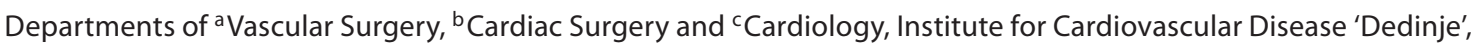 \\ Faculty of Medicine, University of Belgrade, Belgrade, Serbia
}

\section{Key Words}

Age $\cdot$ Atherosclerosis, premature $\cdot$ Risk factors

\begin{abstract}
Objective: The aim of this study was to determine the distribution of major risk factors among patients with atherosclerotic disease aged $\leq 50$ years. Subjects and Methods: The study population comprised 944 patients aged $\leq 50$ years with clinically significant manifestations of atherosclerotic disease compared with 350 consecutive (control) older patients (age $>50$ years). Results: The most significant risk factors for atherosclerotic disease of the supra-aortic branches were: smoking (87.5\%, $p<0.001)$, family history of atherosclerosis $(52.3 \%, \mathrm{p}<0.001)$, diabetes mellitus $(28.5 \%)$ and being male (56.9\%) ( $p<0.05$ for both). In patients with coronary artery disease, there was considerable disparity in the prevalence of smoking (85.4\%), hyperlipoproteinemia (67.4\%), and family history of atherosclerosis $(68 \%)(p<0.001)$. For peripheral artery disease, the most significant risk factors were smoking (97\%, $p<0.001)$, hyperlipidemia ( $p<0.01)$, and family history of atherosclerotic disease $(p<0.01)$. When compared to controls, patients with premature atherosclerosis smoked more frequently, had hyperlipidemia, had a family history of atherosclerosis, and were more frequently of male sex. Conclusion: Premature atherosclerosis was most frequently associated with smoking, hyperlipidemia, family history of atherosclerotic disease, and male sex.
\end{abstract}

Copyright $\odot 2012$ S. Karger AG, Basel
(C) 2012 S. Karger AG, Basel

$1011-7571 / 12 / 0213-0228 \$ 38.00 / 0$

Fax +4161306 1234

E-Mail karger@karger.ch

www.karger.com
Accessible online at: www.karger.com/mpp

\section{Introduction}

Atherosclerosis begins in childhood and progresses from fatty streaks to raised lesions in adolescence and young adulthood [1]. In some studies, as many as $90-95 \%$ of younger patients had one or more traditional risk factors for atherosclerosis and different risk factor profiles, clinical presentations, and prognoses compared to older patients [2-5]. It is important to emphasize that about $60 \%$ of premature coronary artery disease (CAD) clusters in families [6]. Patients under the age of 50 years have an extremely poor prognosis [7-9] while those above 50 years have accelerated development of atherosclerosis and a high incidence of recurrence after revascularization $[10,11]$. The most common atherosclerotic risk factors include smoking as well as arterial hypertension (HTN), hyperlipoproteinemia (HLP), diabetes mellitus (DM), and family history of atherosclerotic disease [1116]. Premature atherosclerosis is a very complex problem for individuals and society in general because of its aggressive course and the frequent occurrence of complications. The high cost of treatment, sick leave, and permanent disability represent serious and economic social problems because they affect the working population. Among young people, the risk of developing cardiovascular disease (CVD) has increased due to lifestyle changes, work- and family-related stress, and failure to effectively control the major risk factors. 
Therefore, the primary aim of this study was to determine the distribution of major risk factors (smoking, HTN, HLP, DM, and family history of atherosclerotic disease) among patients aged $\leq 50$ years treated surgically or endovascularly during 2009. A secondary aim was to examine the correlation of risk factors with localization of the atherosclerotic process in these patients younger than 50 years of age.

\section{Subjects and Methods}

The study was conducted at the University Cardiovascular Clinic. The study population comprised 944 patients $\leq 50$ years of age (range 24-50) with clinically significant manifestations of atherosclerotic disease of coronary arteries, supra-aortic branches, and/or peripheral arteries (aortoiliac and infrainguinal regions) which required surgical or endovascular treatment. $\mathrm{Pa}$ tients with arteritis, aneurysms, pseudoaneurysms, or acute or chronic complications of aortic dissections were excluded from analysis. The following risk factors were analyzed: sex, smoking, HTN, HLP, DM, and family history of atherosclerosis disease. The distribution of risk factors and the correlation with localization of the atherosclerotic process were examined in these patients who were hospitalized during 2009. A control group of 350 consecutive patients older than 50 years of age (range 51-81) treated surgically or endovascularly between January 1 and April 2, 2009, was selected for comparison. The presence of risk factors was determined by anamnestic data, available medical documentation, and laboratory tests. Participants were classified as smokers if they were currently smoking, irrespective of the cigarettes smoked daily. HLP was defined as low-density lipoprotein values $>160 \mathrm{mg} / \mathrm{dl}$ or total cholesterol $\geq 240 \mathrm{mg} / \mathrm{dl}$ or use of lipid-lowering agents. Participants were considered hypertensive if their systolic blood pressure was above $140 \mathrm{~mm} \mathrm{Hg}$ and/or their diastolic blood pressure was above $90 \mathrm{~mm} \mathrm{Hg}$ and/or the subject both selfreported a history of HTN and was taking antihypertensive drugs. DM was defined as fasting blood glucose above $1.26 \mathrm{~g} / \mathrm{l}$ or use of antidiabetic drugs. A positive family history was defined as $\geq 1$ first degree and/or $\geq 2$ second degree family members with CVD before the age of 55 years in men and 60 years in women. Supra-aortic branch disease was defined as common and internal carotid, vertebral, subclavian, and innominate artery disease. Peripheral arterial disease was defined as steno-occlusive aortoiliac and infrainguinal arterial disease.

It is a general policy at our institution that, upon admission, patients have to sign an informed consent form that allows the use of their data for retrospective analysis. Also, approval from the local ethical committee for the particular study was obtained.

\section{Statistical Analysis}

All data are expressed as means \pm standard deviation. A t test was used for comparisons between the subgroups for continuous variables, and a $\chi^{2}$ test was used for comparison between the subgroups for categorical variables $(\mathrm{p}<0.05$ was considered statistically significant).

Risk Factors for Premature

Atherosclerosis

\section{Results}

Of the 944 patients in the study group, 781 had CAD, 88 had supra-aortic branch disease, and 75 had peripheral artery disease. Of the 350 patients in the control group, 243 had CAD, 61 had supra-aortic branch disease, and 46 had peripheral artery disease.

\section{Coronary Artery Disease}

Of the 781 patients in the study group, 477 (61.6\%) were men and $304(38.4 \%)$ were women with a mean age of $45.6 \pm 5.5$ years. Of the 243 patients in the control group, 139 were men and 104 were women, respectively, with a mean age of $63.9 \pm 7.6$ years (range $51-81$ ). In patients younger than 50 years of age, single-vessel disease was found in $272(35 \%)$ cases (most commonly right coronary artery: $n=171)$. Among these patients, 241 were treated with percutaneous coronary intervention, and 31 were treated surgically (mostly combined with valvular treatment). Two-vessel disease was found in 268 (34\%) patients (surgical, $\mathrm{n}=144$; percutaneous intervention, $\mathrm{n}=124)$. Patients with three-vessel disease and more ( $\mathrm{n}=$ $241)$ were mainly treated surgically $(n=184)$. On the other hand, in patients older than 50 years of age, 131 (54\%) were revascularized surgically (three-vessel disease in 81 patients, two-vessel disease in 46 patients, and single-vessel disease in 4 patients). A total of 112 patients (46\%) were treated endovascularly (49 patients with single-vessel disease, 54 patients with two-vessel disease, and 9 patients with three-vessel disease).

Patients in the study group had a significantly higher incidence of smoking (85.4 vs. 56\%), HLP (67.4 vs. $46.1 \%$ ), and family history of atherosclerotic disease (68 vs. $42.4 \%$ ) compared with those in the control group $(\mathrm{p}<0.001$, $\mathrm{p}<$ 0.001 , and $p<0.001$, respectively). There were no significant differences between the study and control groups with respect to gender ( 61.6 vs. $57.2 \% ; \mathrm{p}=0.281)$ and the presence of HTN (79 vs. 78.2\%; $\mathrm{p}=0.787)$ and DM (39.1 vs. $44.1 \% ; \mathrm{p}=0.167)($ table 1$)$.

\section{Supra-Aortic Branch Disease}

The study group consisted of 88 patients ( 50 men and 38 women) with an average age of $47.4 \pm 3.1$ years (range $37-50)$. Most of the patients $(n=69)$ were treated surgically; 65 underwent internal carotid artery (ICA) endarterectomy, 1 had endarterectomy of the common carotid artery (CCA), and 3 underwent surgery of the subclavian artery (SA). Nineteen patients underwent endovascular treatment (2 ICA, 4 CCA, 11 SA and 2 vertebral artery angioplasty). In the control group there were 61 patients with 
Table 1. Demographics and risk factors for patients with CAD

\begin{tabular}{|c|c|c|c|}
\hline Demographics & $\begin{array}{l}\text { Patients aged } \\
\leq 50 \text { years } \\
(\mathrm{n}=781)\end{array}$ & $\begin{array}{l}\text { Patients aged } \\
>50 \text { years } \\
(n=243)\end{array}$ & $\begin{array}{l}\mathrm{p} \\
\text { value }\end{array}$ \\
\hline Age (mean $\pm S D)$, years & $45.6 \pm 5.5$ & $63.9 \pm 7.6$ & \\
\hline Male sex & $477(61.6 \%)$ & $139(57.2 \%)$ & 0.281 \\
\hline \multicolumn{4}{|l|}{ Risk factors } \\
\hline Smoking & $667(85.4 \%)$ & $136(56.0 \%)$ & $<0.001$ \\
\hline HTN & $617(79.0 \%)$ & $190(78.2 \%)$ & 0.787 \\
\hline HLP & $526(67.4 \%)$ & $112(46.1 \%)$ & $<0.001$ \\
\hline $\mathrm{DM}$ & $305(39.1 \%)$ & $107(44.1 \%)$ & 0.167 \\
\hline Family & $531(68.0 \%)$ & $103(42.4 \%)$ & $<0.001$ \\
\hline
\end{tabular}

Family $=$ Family history of atherosclerotic disease

Table 2. Demographics and risk factors for patients with supraaortic branch disease

\begin{tabular}{|c|c|c|c|}
\hline Demographics & $\begin{array}{l}\text { Patients aged } \\
\leq 50 \text { years } \\
(\mathrm{n}=88)\end{array}$ & $\begin{array}{l}\text { Patients aged } \\
>50 \text { years } \\
(\mathrm{n}=61)\end{array}$ & $\begin{array}{l}\mathrm{p} \\
\text { value }\end{array}$ \\
\hline Age (mean $\pm S D)$, years & $47.4 \pm 3.1$ & $60.8 \pm 6.6$ & \\
\hline Male sex & $50(56.9 \%)$ & $27(44.2 \%)$ & 0.015 \\
\hline \multicolumn{4}{|l|}{ Risk factors } \\
\hline Smoking & $77(87.5 \%)$ & $35(57.4 \%)$ & $<0.001$ \\
\hline HTN & $67(76.1 \%)$ & $44(72.1 \%)$ & 0.581 \\
\hline HLP & $60(68.2 \%)$ & $32(52.6 \%)$ & 0.052 \\
\hline $\mathrm{DM}$ & $25(28.5 \%)$ & $9(14.7 \%)$ & 0.017 \\
\hline Family & $46(52.3 \%)$ & $17(27.9 \%)$ & $<0.001$ \\
\hline
\end{tabular}

Family = Family history of atherosclerotic disease.

Table 3. Demographics and risk factors for patients with peripheral artery disease

\begin{tabular}{|c|c|c|c|}
\hline Demographics & $\begin{array}{l}\text { Patients aged } \\
\leq 50 \text { years } \\
(n=75)\end{array}$ & $\begin{array}{l}\text { Patients aged } \\
>50 \text { years } \\
(n=46)\end{array}$ & $\begin{array}{l}\mathrm{p} \\
\text { value }\end{array}$ \\
\hline Age (mean $\pm S D)$, years & $46.9 \pm 3.4$ & $60.4 \pm 6.2$ & \\
\hline Male sex & $54(72.0 \%)$ & $28(61.0 \%)$ & 0.204 \\
\hline \multicolumn{4}{|l|}{ Risk factors } \\
\hline Smoking & $73(97.0 \%)$ & $30(65.2 \%)$ & $<0.001$ \\
\hline HTN & $44(59.0 \%)$ & $25(54.4 \%)$ & 0.641 \\
\hline HLP & $38(51.0 \%)$ & $11(24.0 \%)$ & 0.004 \\
\hline DM & $28(37.0 \%)$ & $20(43.5 \%)$ & 0.502 \\
\hline Family & $37(50.7 \%)$ & $10(21.7 \%)$ & 0.003 \\
\hline
\end{tabular}

Family = Family history of atherosclerotic disease. supra-aortic branch disease ( 27 men and 34 women), and their mean age was 60.8 years (range $51-79$, SD 6.6). The majority of patients in the control group $(n=46 ; 75 \%)$ were treated surgically, while $15(25 \%)$ patients underwent endovascular procedures of the supra-aortic vessels (ICA, $\mathrm{n}=8$; CCA, $\mathrm{n}=2 ; \mathrm{SA}, \mathrm{n}=3$, and vertebral artery, $\mathrm{n}=1$ ). The incidence of smoking ( $\mathrm{p}<0,001)$, family history $(\mathrm{p}<$ $0.001), \mathrm{DM}(\mathrm{p}<0.05)$, and male sex $(\mathrm{p}<0.05)$ was significantly higher in the study group as well, with a smoking habit being the most prevalent risk factor (87.5\%) in patients under 50 years of age. There was a trend toward a higher incidence of HLP in younger patients compared to controls. HTN (76.1 vs. $72.1 \%$ ) was more frequent in the study group than in the control group, but the difference was not significant $(\mathrm{p}=0.581)$ (table 2$)$.

\section{Peripheral Artery Disease}

The members of the study group $(\mathrm{n}=75)$ were predominantly men $(n=54 ; 72 \%)$ with a mean age of $46.9 \pm$ 13.4 years (range $36-50$ ). Of these, 54 (72\%) patients were treated surgically, while 21 (28\%) had an endovascular procedure done. The control group consisted of $46 \mathrm{pa}-$ tients (also predominantly male; $61 \%$ ), with a mean age of $60.4 \pm 6.2$ years (range 51-79). In the control group, 37 (81\%) patients underwent bypass surgery, while 9 patients (19\%) were treated endovascularly. The most prevalent of the conventional clinical risk factors was smoking. Although tobacco abuse comprised the majority in both groups, it was significantly more prevalent in the study group $(97 \%)$ than in the control group $(65.2 \%)(\mathrm{p}<0.001)$. No differences were noted between the groups in terms of prevalence of HTN (59 vs. 54.4\%; p = 0.641), DM (37 vs. $43.5 \%$; $\mathrm{p}=0.502)$, and male sex ( 72 vs. $61 \% ; \mathrm{p}=0.204)$ (table 3).

\section{Risk Factors in All Cohorts}

Overall, smoking was the most prevalent risk factor in patients under 50 years of age. Patients in the study group were significantly more likely to be smokers compared with patients in the control group ( 86.5 vs. $57.4 \%$, respectively; $\mathrm{p}<0.001)$. HLP was significantly more prevalent in the study group than in the control group (66.1 vs. $44.3 \%, \mathrm{p}<0.001)$. There were no significant differences between the groups with respect to DM and HTN. Although male sex comprised the majority in both groups, it was significantly more prevalent in the study group ( 61.6 vs. $55.4 \%, \mathrm{p}<0.05)$ than in the control group. Finally, the prevalence of a family history of atherosclerotic disease was significantly higher in patients under 50 years of age $(65 \%)$ than in controls $(37.1 \%$; $p<0.001)$ (ta- 
Table 4. Demographics and risk factors in all cohorts

\begin{tabular}{lllr}
\hline Demographics & $\begin{array}{l}\text { Patients aged } \\
\leq 50 \text { years } \\
(\mathrm{n}=944)\end{array}$ & $\begin{array}{l}\text { Patients aged } \\
>50 \text { years } \\
(\mathrm{n}=350)\end{array}$ & \multicolumn{1}{l}{$\begin{array}{l}\mathrm{p} \\
\text { value }\end{array}$} \\
\hline Age (mean \pm SD), years & $46.6 \pm 4.1$ & $61.7 \pm 6.8$ & \\
Male sex & $581(61.6 \%)$ & $194(55.4 \%)$ & 0.011 \\
Risk factors & & & \\
$\quad$ Smoking & $817(86.5 \%)$ & $201(57.4 \%)$ & $<0.001$ \\
HTN & $728(77.2 \%)$ & $259(74.0 \%)$ & 0.241 \\
HLP & $624(66.1 \%)$ & $155(44.3 \%)$ & $<0.001$ \\
DM & $358(37.9 \%)$ & $136(38.9 \%)$ & 0.758 \\
Family & $614(65.0 \%)$ & $130(37.1 \%)$ & $<0.001$ \\
\hline
\end{tabular}

Family $=$ Family history of atherosclerotic disease.

Table 5. Between-groups analysis based on the number of risk factors observed in single individuals

\begin{tabular}{lccc}
\hline $\begin{array}{l}\text { Number of } \\
\text { risk factors }\end{array}$ & $\begin{array}{l}\text { Patients aged } \\
\leq 50 \text { years } \\
(\mathrm{n}=944)\end{array}$ & $\begin{array}{l}\text { Patients aged } \\
>50 \text { years } \\
(\mathrm{n}=350)\end{array}$ & $\begin{array}{l}\mathrm{p} \\
\text { value }\end{array}$ \\
\hline 0 & $0(0.0 \%)$ & $9(2.6 \%)$ & $\mathrm{NS}$ \\
1 & $108(11.4 \%)$ & $78(22.3 \%)$ & $<0.001$ \\
2 & $127(13.5 \%)$ & $96(27.4 \%)$ & $<0.001$ \\
3 & $234(24.8 \%)$ & $85(24.3 \%)$ & $\mathrm{NS}$ \\
4 & $298(31.6 \%)$ & $54(15.4 \%)$ & $<0.001$ \\
5 & $177(18.7 \%)$ & $28(8.0 \%)$ & $<0.001$ \\
\hline
\end{tabular}

ble 4). Patients younger than 50 years of age more frequently had 4 and 5 risk factors, whereas control group patients more frequently had 1 and 2 risk factors (table 5).

\section{Intragroup Comparison of Risk Factors in Patients Aged $\leq 50$ Years}

Briefly, smoking was more prevalent in patients with peripheral artery disease than in those with atherosclerosis of the supra-aortic branches $(\mathrm{p}<0.05)$ and those with CAD ( $\mathrm{p}<0.01)$. However, HTN was more frequently present in those with CAD $(\mathrm{p}<0.001)$ and in patients with atherosclerosis of the supra-aortic branches $(\mathrm{p}<$ $0.05)$ than in patients with peripheral artery disease. The same was found for HLP ( $p<0.01$ and $\mathrm{p}<0.05$, respectively), as well as for a positive family history of atherosclerosis ( $\mathrm{p}<0.001$ and $\mathrm{p}<0.01$, respectively). There was no difference between the groups in terms of the prevalence of DM.

\section{Discussion}

Atherosclerotic disease in patients younger than 50 years of age has been described as premature atherosclerosis [7]. Our findings that smoking and a family history of atherosclerotic disease were the main risk factors for premature atherosclerosis in young adults confirmed the results of previous studies $[2-5,7,8,11,16]$. In a Bogalusa study [11], the autopsy results showed more distinct symptoms of subclinical atherosclerosis among younger persons with multiple risk factors aged between 2 and 39 years than among persons without risk factors.

\section{Coronary Artery Disease}

Mukherjee et al. [16] examined the risk factors in patients with premature CAD and compared them with older patients. In their series young adult patients were more frequently male and significantly more likely to be smokers. However, HTN (40.8 vs. 58.6\%) and DM (13.6 vs. $23.1 \%)$ were more frequent in the control group. Similarly, Saad et al. [17] in their analysis found a higher incidence of DM in older patients. Contrary to the results of a previous study [16], the majority of patients in both groups had HTN (79 and 78.2\%), but no significant difference was found between young and older patients. However, in agreement with our results, DM is a less prevalent risk factor in patients with premature coronary disease compared with the elderly. Our results are consistent with other studies $[18,19]$ with respect to parental history of atherosclerosis. Chesebro et al. [18] found that family history at a young age was significantly associated with an early onset of CAD. In addition, Friedlander et al. [19] concluded that a family history of myocardial infarction is positively associated with the risk of early myocardial infarction in women.

\section{Supra-Aortic Branch Disease}

In this group the higher incidence of smoking (87.5 vs. 57.4\%; $\mathrm{p}<0.001$ ) among study patients compared with control patients is similar to that in previous studies $[3,4$, $20,21]$, thereby suggesting that younger patients are more likely to be smokers at presentation. For HTN, the approximately equal prevalence in both the study group (76.1\%) and the control group (71.1\%) is similar to the findings of Martin et al. [3] and Ballotta et al. [20]. However, a number of other studies $[4,20,21]$ have reported a higher frequency of HTN in patients less than 50 years of age. Differences with previous studies are noticed with respect to gender and DM. Most articles report [3, 4, 20, 21] similar frequencies of patients with DM and gender distribution, with no 
statistically significant difference between young and older control patients. Our analysis revealed that patients under 50 years of age with supra-aortic branch disease, compared with a randomly selected control group of older patients, had a higher prevalence of DM ( 28.5 vs. $14.7 \%, \mathrm{p}=$ 0.017). Similar results were found with regard to gender; the majority of patients in our study were male (56.9 vs. $44.2 \%, \mathrm{p}=0.015$ ). In addition, a family history of atherosclerotic disease ( 52.3 vs. $27.9 \%, \mathrm{p}<0.001)$ is a statistically significant risk factor for supra-aortic branch disease among young patients. However, to our knowledge, previous studies did not include this risk factor in their analysis.

\section{Peripheral Artery Disease}

Patients in the study group had a significantly higher incidence of smoking, family history of atherosclerotic disease, and HLP as compared with the control group $(\mathrm{p}<0.001, \mathrm{p}=0.004$, and $\mathrm{p}=0.003$, respectively) but were less likely to have HTN or be male ( $p>0.05$ for both). In addition, in this series a higher frequency of DM (37 vs. $43.5 \%$; $\mathrm{p}=0.502$ ) was noted among control patients compared with study patients. In our analysis smoking was the most frequent $(97 \%)$ risk factor among young patients. The results of previous studies $[5,14,22,23]$ have similarly suggested that smoking is strongly associated with atherosclerotic disease of the aortoiliac and infrainguinal region in young adult patients. Among patients with peripheral artery disease, results of age-related studies have reported that $87-100 \%$ of young patients are smokers compared with $64-71 \%$ of older patients $[5,22$, 23]. Also, the frequency of HLP was significantly higher in the study group (51 vs. 24\%). While Mingoli et al. [5] reported a statistical significance of hyperlipidemia in patients with premature peripheral atherosclerosis, Valentine et al. [24] found a similar frequency of HLP in young patients and the control group. In a recent report, Valentine et al. [25] established that individuals with a family history of premature peripheral artery disease are almost three times more likely to have arterial lesions than those with no family history of CVD. The HTN rate in our study was equal in both groups (59 vs. $54.4 \%$ ). In several reports [14, 22-24] and in our analysis, HTN was not found to be as prevalent in patients with an early onset of peripheral atherosclerosis, occurring in 36-56\% of cases, when compared with their older counterparts. This finding differs considerably from the report of Mingoli et al. [4] who found a significantly higher prevalence of HTN among young patients (67.7 vs. $31 \%$, p < 0.001 ).

Harris et al. [22] concluded that young patients with diabetes had lower long-term patency rates, a higher mor- tality rate, and increased rates of early and late major amputation. In addition, the UKPDS [26] study clearly showed that the risk of amputation or death from peripheral vascular disease was closely associated with diabetes. However, consistent with findings of our and numerous studies [5, 22-24], diabetes is a less common risk factor among young patients and affects $9-35 \%$ patients with premature peripheral atherosclerosis.

Our data shows that the distribution of the risk factors for clinically significant premature atherosclerosis in our group is in accordance with the previously published data. However, a potential limitation of the current study is that it focused only on traditional risk factors and not on other biochemical or genetic markers for premature atherosclerosis.

\section{Conclusions}

Our data indicate that smoking, a positive family history of atherosclerotic disease, DM, and male sex are associated with atherosclerosis of the supra-aortic branches. Incidences of smoking habit and HLP and a family history of atherosclerosis are significantly more frequent in younger adults with CAD. Smoking represents the most widespread risk factor for patients with peripheral artery disease. Also, younger adults with supra- and infra-inguinal atherosclerotic disease have a higher prevalence of HLP and a family history of atherosclerosis. Overall, smoking, HLP, family history of atherosclerosis, and male sex were the most prevalent risk factors in patients under 50 years of age.

\section{Acknowledgement}

This study was partly funded by grant No. 41002 from the Ministry of Science and Technological Development of the Republic of Serbia.

References

1 Barker DJ, Winter PD, Osmond C, Margetts B, Simmonds SJ: Weight in infancy and death from ischaemic heart disease. Lancet 1989;334:577-580.

2 Choudhury L, Marsh JD: Myocardial infarction in young patients. Am J Med 1999;107: 254-261.

3 Martin GH, Allen RC, Noel BL, Talkington CM, Garrett WV, Smith BL, Pearl GJ, Thompson JE: Carotid endarterectomy in patients less than 50 years old. J Vasc Surg 1997;26:447-454. 
4 Levy PJ, Olin JW, Piedmonte MR, Young JR, Hertzer NR: Carotid endarterectomy in adults 50 years of age and younger: a retrospective comparative study. J Vasc Surg 1997; 25:326-331.

5 Mingoli A, Sapienza P, Feldhaus RJ, di Marzo L, Burchi C, Cavallaro A: Aortoiliofemoral bypass graft in young adults: long-term results in a series of sixty-eight patients. Surgery 1997; 121:646-653.

-6 Boer JM, Feskens EJ, Verschuren WM, Seidell JC, Kromhout D: The joint impact of family history of myocardial infarction and other risk factors on 12-year coronary heart disease mortality. Epidemiology 1999; 10: 767-770.

-7 Hansen ME, Valentine RJ, McIntire DD, Myers SI, Chervu A, Clagett GP: Age-related differences in the distribution of peripheral atherosclerosis: when is atherosclerosis truly premature? Surgery 1995;118:834-839.

-8 Evans WE, Hayes JP, Vermillion BD: Atherosclerosis in the younger patient: results of surgical management. Am J Surg 1987;154: 225-229.

9 Brunkwall J, Weibull H, Bergqvist D, Takolander R, Bergentz SE: Arterial surgery and angioplasty in patients under 40 years of age: a retrospective study. Med Princ Pract 1989; $1: 37-43$.

10 Valentine RJ, Myers SI, Hagino RT, Clagett GP: Late outcome of patients with premature carotid atherosclerosis after carotid endarterectomy. Stroke 1996;27:1502-1506.

- 11 Berenson GS, Srinivasan SR, Bao W, Newman WP 3rd, Tracy RE, Wattigney WA: Association between multiple cardiovascular risk factors and atherosclerosis in children and young adults: the Bogalusa Heart Study. N Engl J Med 1998;338:1650-1656.
2 Freedman DS, Khan LK, Dietz WH, Srinivasan SR, Berenson GS: Relationship of childhood obesity to coronary heart disease risk factors in adulthood: the Bogalusa Heart Study. Pediatrics 2001;108:712-718.

13 Porkka KV, Viikari JS, Taimela S, Dahl M, Akerblom HK: Tracking and predictiveness of serum lipid and lipoprotein measurements in childhood: a 12-year follow-up the Cardiovascular Risk in Young Finns study. Am J Epidemiol 1994;140:1096-1110.

14 Barretto S, Ballman KV, Rooke TW, Kullo IJ: Early-onset peripheral arterial occlusive disease: clinical features and determinants of disease severity and location. Vasc Med 2003;8:95-100.

15 de Jongh S, Lilien MR, Bakker HD, Hutten BA, Kastelein JJ, Stroes ES: Family history of cardiovascular events and endothelial dysfunction in children with familial hypercholesterolemia. Atherosclerosis 2002;163:193197.

16 Mukherjee D, Hsu A, Moliterno DJ, Lincoff AM, Goormastic M, Topol EJ: Risk factors for premature coronary artery disease and determinants of adverse outcomes after revascularization in patients $<$ or $=40$ years old. Am J Cardiol 2003;92:1465-1467.

17 Saad H, Sawan S, Rashed W, Zubaid M: Influence of diabetes on the outcome of acute coronary syndrome in Kuwait. Med Princ Pract 2010;19:113-117.

18 Chesebro JH, Fuster V, Elveback LR, Frye RL: Strong family history and cigarette smoking as risk factors of coronary artery disease in young adults. Br Heart J 1982;47: 78-83.
19 Friedlander Y, Arbogast P, Schwartz SM, Marcovina SM, Austin MA, Rosendaal FR, Reiner AP, Psaty BM, Siscovick DS: Family history as a risk factor for early onset myocardial infarction in young women. Atherosclerosis 2001;156:201-207.

20 Ballotta E, Da Giau G, Renon L: Early and late outcomes of young patients after carotid endarterectomy. Surgery 1999;125:581-586.

21 Mingoli A, Sapienza P, Feldhaus RJ, di Marzo L, Sgarzini G, Burchi C, Modini C, Cavallaro A: Carotid endarterectomy in young adults: is it a worthwhile procedure? J Vasc Surg 1997;25:464-470.

22 Harris LM, Peer R, Curl GR, Pillai L, Upson J, Ricotta JJ: Long-term follow-up of patients with early atherosclerosis. J Vasc Surg 1996; 23:576-581.

23 Reed AB, Conte MS, Donaldson MC, Mannick JA, Whittemore AD, Belkin M: The impact of patient age and aortic size on the results of aortobifemoral bypass grafting. J Vasc Surg 2003;37:1219-1225.

24 Valentine RJ, Myers SI, Inman MH, Roberts JR, Clagett GP: Late outcome of amputees with premature atherosclerosis. Surgery 1996;119:487-493.

25 Valentine RJ, Guerra R, Stephan P, Scoggins E, Clagett GP, Cohen J: Family history is a major determinant of subclinical peripheral arterial disease in young adults. J Vasc Surg 2004;39:351-356.

26 Stratton IM, Adler AI, Neil HA, Matthews DR, Manley SE, Cull CA, Hadden D, Turner RC, Holman RR: Association of glycemia with macrovascular and microvascular complications of type 2 diabetes (UKPDS 35): prospective observational study. BMJ 2000;321:405-412. 